\title{
Science 2.0 supported by Open Access Repositories and Open Linked Data
}

\author{
Tránsito Ferreras-Fernández \\ Institutional Repository \\ University of Salamanca \\ Libreros 68, 37008 Salamanca \\ *34 923294500 (ext.1263) \\ transiff@usal.es \\ José A. Merlo-Vega \\ Dep. of Library and Information Sciences \\ University of Salamanca \\ merlo@usal.es \\ Francisco J. García-Peñalvo \\ GRIAL Research Group, \\ Educational Research Institute, University of Salamanca \\ fgarcia@usal.es
}

\begin{abstract} 2.0

\section{Categories and Subject Descriptors}

H.3.7 [Digital Libraries]: Dissemination, Standards, Systems issues

D.2.12 [Interoperability]: Data mapping, Distributed object, Interface definition languages

General Terms

Management, Measurement, Documentation, Design, Standardization.
\end{abstract}

The main goal of this track is to gather experiences and works to disseminate initiatives, programmes and projects about both theoretical and technological issues related to Open Knowledge with regard to two key elements: the open access to the scientific knowledge and Science

\section{Keywords}

Open Knowledge management, Open Access repository, Science 2.0. Open Access technology, Bibliographic description, Interoperability.

\section{INTRODUCTION}

Open Access (OA) [1-2] is still a new concept. Last February 2012 was the 10th anniversary of the Budapest Open Access Initiative (BOAI), the first public declaration about $\mathrm{OA}$ and its infrastructure through the combination of two methods: Gold Open Access, allowing researchers to publish in OA journals, and Green Open Access, allowing researches to place their previously published works in OA repositories with the aim these will be open accessed and reused.

As consequence of the knowledge OA development, and also due to a most implication of the Governments and Institutions regarding OA policies, a very significant increase of OA resources has been achieved through journals and repositories. This rising of the free accessible knowledge and also of the virtual emplacements to store the open resources has caused an improvement of the tools, techniques and, specially, interoperability among repositories, all of them designed to offer solutions in a new complex and decentralized technological ecosystem. This way, the number of OA repositories has increased and they become in a key element of the eResearching infrastructure.

The main goal of this track is to gather experiences and works to disseminate initiatives, programmes and projects about both theoretical and technological issues related to Open Knowledge with regard to two key elements: the open access to the scientific knowledge and Science 2.0, organized in the following blocks:

1. The current theoretical framework of the open knowledge management: repositories and Science 2.0 
2. Open Access technology, where is important to explore technological issues regarding persistence, maintenance, preservation, interoperability and dissemination of the OA repositories, and also its involvement in the Semantic Web throughout the application of Linked Open Data (LOD) schemes.

3. Science 2.0 regarding applications and resources of the Social Web for researching, including the evaluation of these tools too.

\section{TRACK TOPICS}

I. Open Knowledge management: Open Access repository and Science 2.0:

- Science 2.0: The Use of Social Networking in Research

- Science 2.0: Tools and experiences sharing research.

- Science 2.0: Tools and experiences sharing resources.

- Science 2.0: Tools and experiences sharing results.

II. Open Access Technology:

1. Metadata:

- Domain metadata (research institutions, cultural memory institutions, education, government, and scientific fields).

- Metadata for e-Science.

- Metadata principles, guidelines, and best practices.

- Conceptual models and frameworks (e.g., RDF, DCAM, OAIS).

- Metadata uses (preservation, curation, institutional repositories, publishing).

- Social tagging and user participation in building metadata.

- Knowledge Organization Systems (ontologies, taxonomies, authority files, folksonomies, and thesauri) and Simple Knowledge Organization Systems (SKOS).

- Ontology design and development. Integration of metadata and Ontologies.

- Linked data and the Semantic Web (metadata and applications).

2. Open Access Repositories:

- Open Access Repository Interoperability.

- Open Source: Software and Frameworks.

- Services making use of repository metadata.

- Infrastructure for use and reuse of content.

- Semantic Web. Repositories Linked Open Data.

- Added-value services for repositories.

- Long-term preservation of repositories and their contents.

- Role and impact of repositories in the research ecosystem.

III. Bibliographic description and Interoperability:

- Resource Description and Access (RDA).

- Semantic mapping from RDA to metadata schemes.

- Interoperability for digital libraries and repositories.

- Interoperability and Linked Data.

- Metadata interoperability and bibliographic platforms.

\section{TRACK ACCEPTED PAPERS}

\subsection{Linked Open Bibliographic Data}

Ana Ríos-Hilario, Tránsito Ferreras-Fernández and Diego Martín-Campo. Linked Open Bibliographic Data.

It analyzes the application of Linked Open Data (LOD) in the particular case of bibliographic data through examination of two key documents: the Library Linked Data Incubator Group: Use Cases and, more specifically, the section that refers to the bibliographic data cluster and, the Linked Open Data-Enabled Bibliographical Data (LODE-BD). Following the introduction that contextualizes the object of study, it goes on to describe the first of the documents published by the W3C and describes the advantages of the application of LOD in the case of bibliographic data. In the second document, more practical is examined its structure in order to facilitate the publication of bibliographic data as linked open data

The heading of subsections should be in Times New Roman 12-point bold with only the initial letters capitalized. (Note: For subsections and subsubsections, a word like the or $a$ is not capitalized unless it is the first word of the header.) 


\subsection{Interlinking Educational Data: an Experiment with GLOBE Resources}

Enayat Rajabi, Miguel-Angel Sicilia and Salvador Sánchez-Alonso. Interlinking Educational Data: an Experiment with GLOBE Resources.

With the proliferation of educational materials on the Web of Data, interlinking learning resources has become an important issue nowadays. Interlinking datasets over Linked Open Data (LOD) enables enriching, enhances navigation, facilitates casual discovery, and improves resource seeking. To this aim, many tools, approaches and frameworks have been built to discover similarities between entities on the Web of Data. In this paper we evaluate interlinking approach on a huge educational resource (GLOBE) by applying two link discovery tools (LIMES and GoogleRefine). We also report the results of linking the GLOBE to the DBpedia and Factbook datasets and list the advantage of this interlinking process.

\subsection{Metadata Mapping to describe Learning Objects and Educational Apps in the GREDOS Repository}

Morales Morgado Erla Mariela, Rosalynn Argelia Campos Ortuño, Ling Ling Yang and Tránsito Ferreras-Fernández. Metadata Mapping to describe Learning Objects and Educational Apps in the GREDOS Repository.

This paper describes a Project entitled "Divulgación de Recursos Educativos Digitales (DIRED)" (Divulgation of Digital Educational Resources) addressed to promoting specific educational resources and mobile apps for educational proposals through the institutional repository of the Salamanca University (GREDOS). We present a proposal for describing learning objects based on pedagogical information, digital competences and learning styles. We also suggest educational information for classifying useful mobile apps. To achieve this we focus on the use of learning-object specific metadata in digital repositories such as LOM (Learning Object Metadata). We study the metadata mapping necessary to adapt from LOM to Qualified Dublin Core, because this is the standard used in the GREDOS repository built with a DSpace platform. Finally, we present our implementation of Learning Object Description in the GREDOS repository.

\subsection{Impact of Scientific Content in Open Access Institutional Repositories. A case study of the Repository GREDOS}

Tránsito Ferreras-Fernández, José Antonio Merlo-Vega, Francisco José García-Peñalvo. Impact of Scientific Content in Open Access Institutional Repositories. A case study of the Repository Gredos.

In this paper we describe the PhD Thesis Project "Impacto de los contenidos cientificos en repositorios institucionales de acceso abierto. Un caso de estudio del repositorio Gredos de la Universidad de Salamanca" (Impact of Scientific Content in Open Access Institutional Repositories. A case study of the Repository Gredos of the University of Salamanca) into the PhD program called "Información y Documentación" (Information and Documentation) at the University of Salamanca. The working area of this research is the Open Knowledge. We explain that over the last decade the great development of the movement of Open Access has led to the creation of institutional repositories in order to store, disseminate and preserve digital documents of the institutions. Obviously, for researchers and institutions, it is essential to achieve visibility, citation and impact from their researching works. We study the relationship between the Open Access and the scientific impact of the papers. We focus on the PhD theses of the Salamanca University to demonstrate that the theses deposited in its institutional repository, called GREDOS, have more citations and impact that the theses that are not Open Access. We introduce the design of the theoretical part and we explain the goals and the methodology we will use in this study.

\section{REFERENCES}

[1] García-Peñalvo, F.J., García-Figuerola, C., and Merlo-Vega, J.A. 2010. Open Knowledge: challenges and facts. Online Information Review, 34, 4 (2010), 520-539. DOI= 10.1108/14684521011072963

[2] García-Peñalvo, F.J., García-Figuerola, C., and Merlo-Vega, J.A. 2010. Open Knowledge management in higher education. Online Information Review, 34, 4 (2010), 517-519. 